\title{
Technology Renewal, User Resistance, User Adoption: Status Quo Bias
}

\section{Theory Revisited}

\author{
Anuragini Shirish \\ Associate Professor, Université Paris-Saclay, Univ Evry, IMT-BS, LITEM, 91025, Evry- \\ Courcouronnes, France. \\ https://orcid.org/0000-0001-8199-2889
}

Leslie Batuekueno

Graduate, Institut Mines Telecom Business

Published in Journal of Organizational Change Management

DOI: 10.1108/JOCM-10-2020-0332

Please cite as: Shirish, A. \& Batuekueno, L. (2021). Technology Renewal, User Resistance, User Adoption: Status Quo Bias Theory Revisited, Journal of Organizational Change Management, (published ahead of print) [Vol.(Issue), page numbers] DOI:

10.1108/JOCM-10-2020-0332

[This author accepted manuscript is deposited under a Creative Commons Attribution Noncommercial 4.0 International (CC BY-NC) licence. This means that anyone may distribute, adapt, and build upon the work for non-commercial purposes, subject to full attribution. If you wish to use this manuscript for commercial purposes, please contact permissions@emerald.com]

Authours Copy Ahead of Print, the final published manuscript can have some minor changes for type setting purposes. 


\section{Technology Renewal, User Resistance, User Adoption: Status Quo Bias Theory Revisited}

Methodology: We used survey method to gather data. All items were based on prior literature. We administrated the survey to employees of GOODTECH (name changed), information systems department members, situated in France. We obtained 103 valid responses along with usage data from the system to run our path model in order to validate our proposed research model.

Purpose: The article provides a conceptual replication and enrichment of the status quo bias theory in the specific context of understanding IT department user resistance and user adoption. The findings can assist technology renewals and associated change management professionals to assess and plan the adoption and active usage of human resource systems.

Findings: The study offers an enriched user resistance model to understand why IT savvy employees would resist or adopt new human resource tools. Apart from providing partial validity to status quo bias theory in the French context, the enriched model uses behavioral intention to use as an intermediate variable to explain the influence of two key construct of the original theory: Switching cost and Switching benefits. This research provides a better explanatory power to understand the cause of user resistance and new IT use.

Limitations: The sample size used in the study can be considered as a limitation, although power analysis reveals that the results are significant and valid. The context of the study is also limited to one country and to a specific type of information systems implementation scenario. Since the purpose of the paper was to offer contextual theory enhancement, therefore the findings are valid for this purpose. 
Practical Implications: Digital project managers are offered a framework to increase technology adoption of new human resource tools and evaluate how to reduce user resistance at times of technology renewals. Self-efficacy for change and colleagues opinion can indirectly impact behavioral intention to use via switching cost and switching benefit perceptions and thus reduce resistance perceptions as well as increase adoption of new IT tools in post implementation phases.

Originality: The paper enriches the well-established user resistance theory (URM) in information systems domain in a context of human resource post implementation phase by studying IT savvy end user's perception. The paper demonstrates the need to integrate user adoption and user resistance variables in one parsimonious framework and extends support to emerging research in this area.

Keywords: Technology renewal, digital transformation projects, human resource systems, IT department employees, status quo bias, user resistance, technology adoption, IT use, change management, France. 


\section{Introduction}

With the growing need of digitalization, information systems (IS) implementation projects are ever increasing. The implementation of a new IS, often undertaken as a technology renewal comes with the notion of change and management of tensions within organizations (Wimelius et al., 2020). Organizations invest in information technology to gain productivity and innovation gains (Chandra et al., 2020), nevertheless, these benefits are reliant on the successful implementation of new IT tools and their adoption by stakeholders. Human reaction to change puts resistance to change as a core and unavoidable concept to any change initiative (Lee \& Joshi, 2017; Visinand, 2004; Zahir Irani, 2000). Human resource is one of the least equipped and most promising function that can benefit from technology renewals and change management initiatives with companywide impact (Forbes, 2020). Thus, it is important to focus both on the IT resistance and IT usage when examining the implementation of a new HR tool as part of a digital transformation project in its unique context to advance theory and practice (Dennis et al., 2020).

Adoption and resistance are twin concepts that go hand in hand with any digital transformation or change management initiatives. User resistance has been defined by Collerette et al. (1997) as an implicit or explicit defense's expression towards a change. Thus, resistance to change is a seen as something that organizations should strive to remove (Kossek et al., 1994). Some other scholars also see it as a way to identify user level frustrations linked to a flawed information system management (Marakas \& Hornik, 1996).

Previous research on user resistance has mainly explained the cause of resistance to change amongst end users who are not particularly tech savvy employees. First stream of research speaks about the role of the user and their knowledge loss perceptions as the primary cause of the resistance (Bareil, 2004; Dent \& Goldberg, 1999). The second finds its roots in 
the quality of the implementation and thus puts the onus on the organizations undertaking the IT implementation and the change to be the cause of resistance and adoption issues. Third stream explains that the expectation of repeated change itself causes resistance, which then translates to the failure of the implementation of change programs in organizations (Abrahamson, 2004).

More specifically, within the information systems (IS) domain, several scholars have studied IT user resistance in particular (Lapointe \& Rivard, 2005; Markus, 1983) but they call for more context oriented implementation examination (Dwivedi et al., 2015). Appendix 1 provides a table summarizing the key research in IT use and resistance. Out of the various theoretical perspectives, one of the most holistic framework to investigate the phenomenon of user resistance in an applied setting is the status quo bias perspective (Kim \& Kankanhalli, 2009). Status quo bias theory (URM) aims to explain people's preference for maintaining their IT use current status and accounts for the loss and the threat perceptions experienced by an end user of an IT tool (Kim \& Kankanhalli, 2009). This theory is particularly amenable to studying both user adoption and user resistance as it offers an integrative model for adoption of IT tools for further investigation. However, past studies have not attempted to enrich this model by incorporating IT adoption concepts. Dual focus of IT use and IT resistance research stream is a new emerging field that requires further investigation (Beaudry et al., 2020).

It may not appear to be ill logical to assume that employees working in IT departments of organizations send a signal through their express choice of career path that they are competent in information systems management and indeed have affective connection to using new IT tools (Paré \& Jutras, 2004). They are often considered as frontline change agents and many digital transformation projects depend on their early adoption to new IT tools to gauge their change management effectiveness. IT employees are prone to be more open to experimentation with new ITs due to their opportunity technology framing (Shirish, 2020b). 
New IT tools introduction in the organization should ideally trigger such employees of the IT department to cope better with the change due to their general positive affect towards IT use (Shirish, 2020b). Recent research also calls for treating IT professionals as new stakeholders when investigating IS success and failure phenomenon(Kim \& Kishore, 2019).

However, thus far, researchers have not investigated user resistance perceptions amongst IT professionals from a status quo bias perspective. Status quo bias theory is a cognitive theory that explains resistance and adoption decisions as an evaluative judgement of the end user (Lee \& Joshi, 2017). The relative value perception from changing their system use from an incumbent to a new system is shown to be linked to resistance perceptions. However, we know that absence of resistance does not preclude the presence of use (Polites \& Karahanna, 2012) thus studying the behavioral intention to use the new technology is taken in this study as the linking variable to explicate this evaluative judgement of end users when they try to manage demands of technology renewals. However, URM theory originated in the North American context. It is important to extend the generalizability of the theory to European context specifically amongst IT professionals to offer contextual clarity and enrich the literature in this domain (Dennis et al., 2020; Johns, 2006). In order to address these research gaps and offer a contextual enrichment that can provide managerial implication to change management initiatives in organizations, we seek to address the below research question in this study:

R1: In the specific context of a technological renewal initiative within a French company, what are the factors that contribute to IT user resistance and IT usage amongst IT professionals?

This study aims to extent previous research that explores the reasons for user resistance to the specific population of IT savvy end users who are often preferred as change agents in digital transformation projects. Their evaluation of change related to new information system and decision to resist it or adopt it is an important void unexplored in literature. In particular, 
the phenomenon of status quo bias amongst IT savvy employees and its influence on their IT adoption or resistance as a dual phenomenon is under examined despite their crucial role in technology renewal and IT project success initiatives. This study leverages the status quo bias theory and adoption literature to conceptually replicate and enrich the theory in the context of a post implementation of human resource (HR) information systems in a European context. To undertake the study, we gathered data from a French company via survey and objective data of system usage. Our results support the proposed enriched user resistance model empirically. Behavioral intention to use the new HR tool investigated in the study was found to be an intermediate variable that explained user resistance and IT use. The results of the study offer both theoretical and practical implications to manage resistance and change amongst IT savvy employees more specifically.

We provide the investigative context and theoretical background in the following two sections of the paper. Followed by the hypothesis development section. Subsequently, we elaborate separately on the method, results and implications of the study

\section{Investigative Context and IT Tool}

The objective of this study is to empirically test user resistance model (URM) to concomitantly explicate IT user resistance and IT usage amongst IT savvy employees. The study will allow us to understand the factors leading to user adoption and user resistance in the specific context of a human resource (HR) IT tool implementation in a large French multinational corporation (MNC) called GOODTECH (pseudonym) with its headquarters in Paris. The authors designed the study to understand why the uptake of a new HR tool was not satisfactory in GOODTECH. The new HR IT tool that was introduced within its broad digital transformation project agenda involved streamlining work practices by introducing technology renewals in HR project reporting. The digital transformation project involved progressive 
change introduction. Users of the IT department of the MNC were chosen to be the first support unit of the company that is required to switch to the new HR tool and it is expected that the transformation would then extend to other primary and support functions incrementally within the GOOGTECH.

My Kaalsheet (name changed), is an internal tool developed by the HR IT department of GOOD TECH. It is a time entry tool that allows user to self-enter their timesheets, extra hours and absences. It was developed in parallel to two other tools that exist within the company and that allows to do the same actions: the Java Portal and Quick Time. Since there were three tools with the same usage context, the company decided to allow the HR IT department to decommission the two others, knowing that My Kaalsheet is the more efficient out of the three of them. Despite this preferred transition, only $30 \%$ of the employees were using the tools since it was released in 2017.

\section{Enriched User Resistance Model: Theoretical Framework}

Appendix 1 of the paper provides a detailed overview of various key papers discussing IT resistance and use in general. In this section, we elaborate on the specific theoretical lens used for this study. The status quo bias theory (Samuelson \& Zeckhauser, 1988), the theory of planned behavior (Ajzen, 1991) and the equity implementation model (Joshi, 1991) were integrated to come up with a holistic theory called user resistance model (Kim \& Kankanhalli, 2009). This theory explains the physiological factors for user resistance of a new IT tools. This theory is called the user resistance model (URM) and it takes into account how human behavior (IT user resistance) can be guided by various beliefs that the user may hold. The development of this theory needed integration of behavioral, normative and control beliefs. Behavioral beliefs are about the potential outcome to IT user resistance as may be perceived by the end user. Normative beliefs are about the other oriented expectations and the motivation to comply 
with such expectations. Control beliefs are those that take into account the perceptions of factors that facilitate or impede the performance of IT user resistance and their respective power perceptions on the particular behavior. Although this theory explains user resistance to IT, the authors of the study also mention that it can be used to study adoption behavior (Kim \& Kankanhalli, 2009). However, prior research has so far not integrated user adoption variable into the model that is a crucial gap we plan to address in this paper.

URM theory explains user resistance through the key variables of switching cost, switching benefits, which then influence their attitude measured as 'perceived value'. Perceived value is then shown to reduce or increase user resistance behaviors to a new IT tool. However, this seminal work was set in the context of pre-implementation of an IT tool. The study was conducted within a major IT service company that was deploying a new enterprise portal and knowledge management system. This tool studied was not a human resource management tool that we study in this paper rather it was a tool for enterprise-wide collaboration and knowledge management functions (Kim \& Kankanhalli, 2009). Data was gathered via a survey from general employees from various functional units of the company as opposed to IT savvy employees as we do in this paper.

The study could not prove all the laid out hypothesis empirically, see Figure 1 of model proposed by (Kim \& Kankanhalli, 2009). The study posited that self-efficacy for change, organizational support for change can both directly impact user resistance and indirectly impact user resistance via switching costs perceptions. The study also posited that colleague's opinion can have a direct impact on user resistance as well as impact both switching cost and switching benefits perceptions. However, the empirical setting used in that study allowed the authors to only confirm certain hypotheses (see Figure 1). 
Over the past years, the status quo bias perspective has been used in various studies starting from the exploration of the adoption of new technology implementation as cloud system (Fan et al., 2015) to exploring the use of an online health service (Xiaofei et al., 2020). However, among these studies there is a lack of representation of the status quo bias perspective on IT department employees in a French context. There is little research focusing on analyzing IT user resistance and IT adoption among IT professionals more generally. There has been prior studies on resistance amongst implementers of IT tool by IT professionals (Lapointe \& Rivard, 2005), but IT department employee in the context of this study are not viewed as implementers in our study context they are mere users. Therefore there is need to revisit their user resistance perspective in the given context.

A brief definition of the various variables used in the enriched URM model are provided in the table below. For the purpose of this study, we are also interested in studying behavior intention to use the new IT tool. We defined it "as the degree to which a person has formulated conscious plans to adopt the new IT tool or not adopt the new IT tool in the future"(Warshaw \& Davis, 1985) (p. 214).

\begin{tabular}{|l|l|l|}
\hline Concepts & Definitions & Source \\
\hline Switching cost & $\begin{array}{l}\text { The perceived disutility a user would } \\
\text { incur in switching from the status quo } \\
\text { to the new IS }\end{array}$ & Kim \& Kankanhalli, 2009) \\
\hline Switching benefit & $\begin{array}{l}\text { The perceived utility a user would } \\
\text { enjoy in switching from the status quo } \\
\text { to the new IS }\end{array}$ & (Kim \& Kankanhalli, 2009) \\
\hline Self-efficacy for change & $\begin{array}{l}\text { The internal means an individual } \\
\text { deploys to gain control over a changing } \\
\text { situation }\end{array}$ & (Ajzen, 1991; Ajzen, 2002) \\
\hline Organizational support & $\begin{array}{l}\text { The perceived facilitation provided by } \\
\text { the organization to make users' } \\
\text { adaptation to new IS-related change } \\
\text { easier. }\end{array}$ & (Kim \& Kankanhalli, 2009) \\
\hline Colleague opinion & $\begin{array}{l}\text { The perception that colleagues favor } \\
\text { the changes related to a new IS } \\
\text { implementation. Due }\end{array}$ & (Kim \& Kankanhalli, 2009) \\
\hline
\end{tabular}

Table 1: Definitions of key concepts in URM model

Although URM provides an integrative framework, the results may vary when a different set of IT tools are studied and when the context of the study may be different. 
Therefore, a conceptual replication may be necessary (Dennis et al., 2020). A recent research that called for such work using URM dealt with the context of specific health IT tool (Samhan \& Joshi, 2019). Therefore, we believe that it is theoretically and practically important and novel to re-examine and expand the URM model in the specific context of IT savvy employees who may be working within various IT departments in a distributed manner but under one large enterprise.

Further, we posit that since we use URM theory in a post implementation of HR IT tool scenario, it becomes important to measure the phenomenon that is beyond the current attitude measure of "perceived value" to see if switching costs and switching benefit can also impact "behavioral intention to use" the new HR tool (Polites \& Karahanna, 2012). This indirect relationship is perhaps more accurate than measuring its precursor. We therefore enrich the URM model by introducing behavioral intention to use as an intermediate variable between independent variables of switching cost and switching benefit on both user resistance and user adoption of the new HR tool amongst IT savvy employees.

Absence of resistance does not mean presence of usage (Polites \& Karahanna, 2012). Inertia in an IS context is defined as user attachment to, and persistence in, using an incumbent system (i.e., the status quo), even if there are better alternatives or incentives to change(Polites \& Karahanna, 2012). So, it becomes important to study IT professionals inertia related factors as well as usage related factors to understand under what conditions we can expect them to become early adopters of new HR technology in the context of a technology renewal digital transformation projects. The research model below provides the extension of the URM theory (see figure 2) and below, we list out the new relationships argued by this study specifically. We do not revisit in an elaborate manner the hypothesis already developed in prior study of Kim and Kankanhalli (2009) for brevity reasons. 


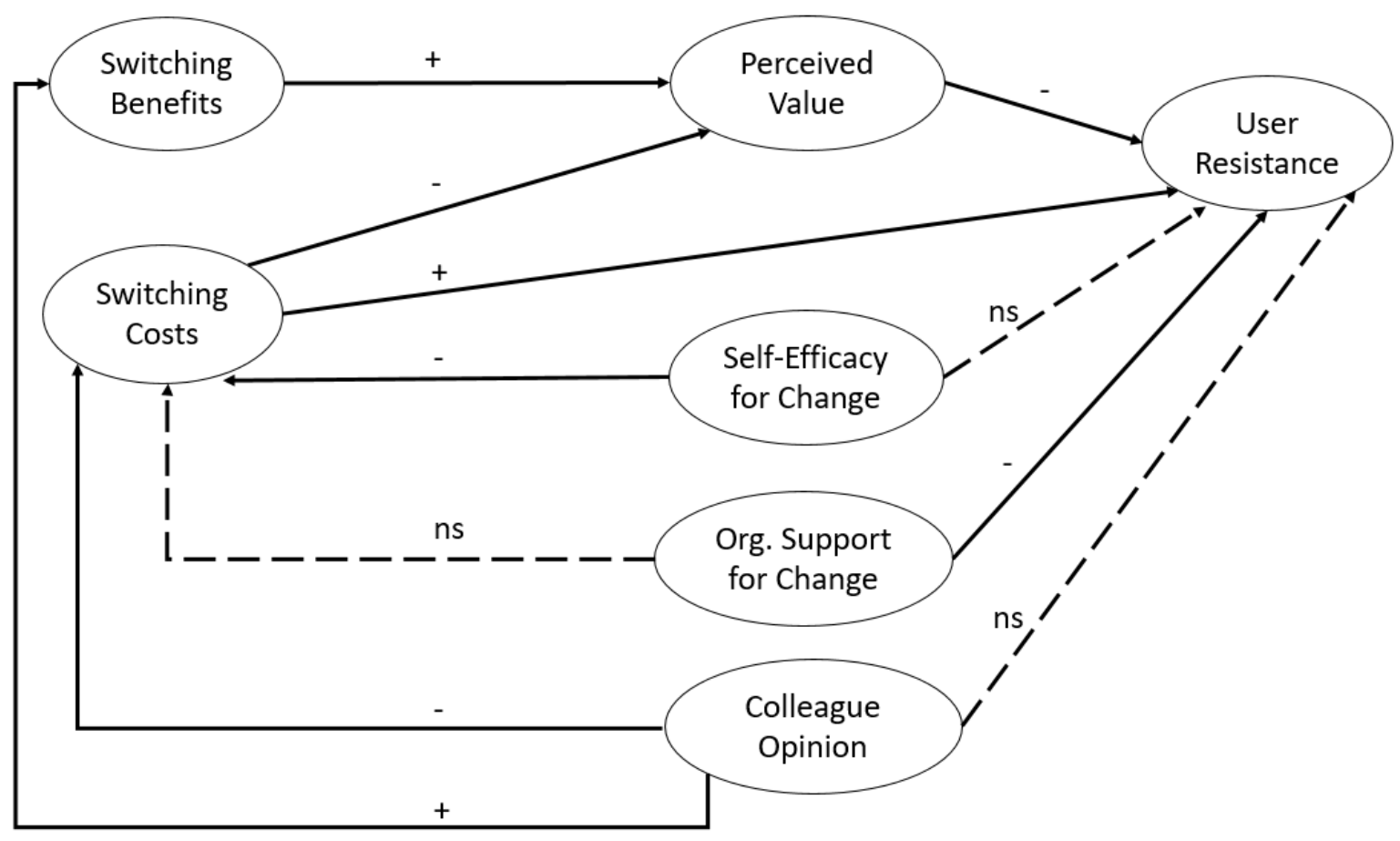

Figure 1. Adapted from (Kim \& Kankanhalli, 2009)

Organizational support was one of the variable in the URM theory. It is defined as the perceived facilitation provided by the organization to make users ' adaptation to new IS-related change easier (Kim \& Kankanhalli, 2009) in the effort of gaining control over the change situation (Samuelson \& Zeckhauser, 1988) organization support have been found to fulfill the same purpose. Facilitating conditions through training and resources supported by the organization can affect the user adaptation and reaction to new IS change (Hirschheim \& Newman, 1988). These new conditions could influence the perceived effort expectation of users adapting to the new IT. Thus, a higher organizational support would mean reduce user resistance toward the new IT-related change as well more use of the new IT tool (Kim \& Kankanhalli, 2009). Since we wanted to focus on the novel indirect relationship in this model, we chose to focus on key antecedents to switching costs and benefits more specifically. We have controlled for organization support in the research model instead of hypothesizing the direct and indirect relationship in this study. 


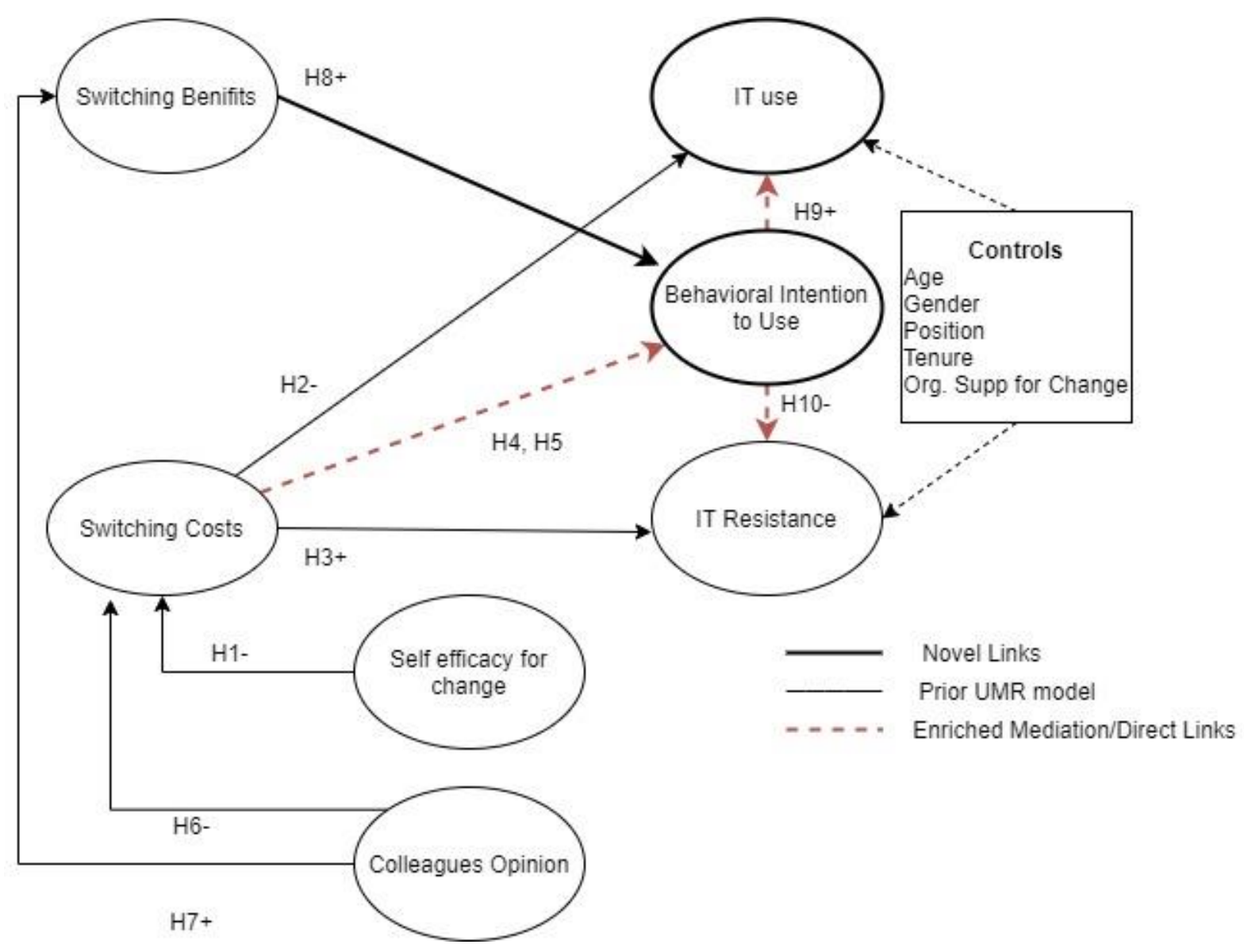

Figure 2. Research Model: Enriched User Resistance and Adoption Model

\section{Hypothesis Development}

This study aims to understand the key factors that influence IT department users either to resist or to use the implementation of a new HR IT time entry tool, My Kaalsheet. These users are unique presumed to be at ease with new technologies. We posit that this IT culture may have a contextual influence on the adoption levels or the resistance levels (Dwivedi et al., 2015). To know how does the status quo bias perception affect a population often considered as informal change champions in organization is interesting and useful.

We used the structural model (Figure 1) of the status quo bias perspective initiated by Kim and Kankanhalli (2009) as the basis of our research model (Figure 2). We extended the model by introducing the construct of actual IT use as another depended variable and the 
behavioral intention to use a mediator between switching cost and IT use/User resistance. In addition, control variables were included in the new conceptual model (Figure2). Tenure, position, age and gender, organization support for change were added as controls (Polites \& Karahanna, 2012)

As per the status quo bias perspective, self-efficacy for change is derived from the construct on control perceptions. Self-efficacy is defined by Sam et al. (2005) as the judgements a person makes about his or her ability to use technologies. If users have a strong self-efficacy for change, then they will be less likely to feel anxious or uncertain regarding the change (Bandura, 1995; Compeau et al., 1999). In contrast, they should feel confident with the adaption to the new IT and learning new technologies. Indeed, a high self-efficacy for change will decrease the transition cost and uncertainty cost, which lower the perception of switching cost. This self-efficacy for change perception, should be more in IT professionals.

According to Kim and Kankanhalli (2009), switching costs is the perceived disutility a user would incur in switching from the status quo to the new IS and is composed of three components: transition costs, uncertainty costs, and sunk costs (Samuelson \& Zeckhauser, 1988). Transition costs are composed of the fee and permanent losses that incurred within the change situation (Kahneman \& Tversky, 1979). The feeling of incompetence toward uncertain situation can bring anxiety and reluctance in the decision making and behavior(Brown \& Venkatesh, 2005). Hence, uncertainty causes negative psychological reaction (Inder \& O'Brien, 2003) which leads users to rely on the status quo (Samuelson \& Zeckhauser, 1988), thus a high level of switching cost perceived in the transition cost and the uncertainty, will decrease the actual use of the tool as well increase the user resistance to the tool. Similarly, we expect a direct influence of switching cost on user resistance (Kim \& Kankanhalli, 2009). Due to reasons already stated above, the perception of uncertainty and transition cost can increase the 
reluctance of people toward change willing to cut the losses incurred (Kahneman \& Tversky, 1979). The negative psychological reaction provoked by the increase of expenses and losses can lead to status quo bias (Samuelson \& Zeckhauser, 1988). The change needed from the past investment over the investment needed in the present, is viewed as a sunk cost, leading to user resistance (Samuelson \& Zeckhauser, 1988). Therefore, higher the switching cost will mean higher the user resistance. Thus, we posit the below:

H1: Self efficacy for change will negatively impact switching cost.

H2: Switching cost will negatively impact IT use.

H3: Switching cost will positively impact IT user resistance

Switching cost as negative psychological reactions can lead to a negative behavior intention to use a technology. Thus, we expect an indirect effect of behavior intention to use on the above relationship of switching cost and actual use already hypothesized. Venkatesh et al. (2003)(p.426) estimates that the reaction of an individual toward the use of IT "affects the formation of their behavioral intention to accept the technology which encourages their active application later". The behavior intention to use construct is derived from the enriched technology adoption model also called as UTAUT2 (Venkatesh et al., 2012). It is defined as "the degree to which a person has formulated conscious plans to perform or not perform some specified future behavior"'(Warshaw \& Davis, 1985) (p.214). The construct is a mental assessment in which an individual decides whether he or she will act according to their expected plan and describes how near they have come to the decision. It correlates with the rational decision-making process describes in the status quo bias theory. According to the UTAUT2 (Venkatesh et al., 2012), behavior intention is influenced by external factors such as the effort expectancy, the perceived ease of use and the social influence to name a few. However, in this study, we expect that due to the post IT implementation scenario in which data was collected it is appropriate to go beyond "perceive value" attitudinal perception in the 
URM and look at the actual intention to use the technology as a valid substitute measure. Past studies show that incumbent system usage constructs can be directly linked to behavior intention to use new systems (Polites \& Karahanna, 2012). Thus, behavior intention to use construct should mediate the relationship between switching costs on the actual use and user resistance of the My Kaaltime. Thus, we posit the below:

H4: Behavior intention to use mediates the relationship between switching cost and IT use.

H5: Behavior intention to use mediates the relationship between switching cost and IT user resistance.

Colleagues are generally the essential point of reference in matters relating to work, which means that through the influence of social norms their opinion about the change to a new IS can heavily influence their comrade's initial perceptions about switching costs and benefits (Burnkrant \& Cousineau, 1975). Positive colleague's opinion toward the new IT tool can serve to decrease uncertainty, which can lead to a lower perception of switching costs. Favorable colleague opinion can also benefit in their decision about the net benefit of the new IS-related change which in turn will lead them to have lower switching cost perceptions and higher switching benefit perceptions. Switching benefit refers to "the perceived utility a user would enjoy in switching from the status quo to the new IS" (Kim \& Kankanhalli, 2009). Thus as per the URM theory (Kim \& Kankanhalli, 2009) we assert that a favorable colleagues' opinion should positively impact switching benefit perceptions. Thus, we posit the below:

H6: Favorable colleagues opinion will have a negative impact on switching cost H7: Favorable colleagues opinion will have a positive impact on switching benefit

As abovementioned, behavior intention to use is an individual assessment and describes how near an individual has come to the usage decision. Switching benefit perception will provide them the reasons to try to use My Kaalsheet instead of the old systems, as it is a proxy to 
measure their evaluation that the new tool is considered to provide superior performance than the old tools. Thus, due to the perceived value perception (implied) they should also perceive behavioral intention to use the new HR tool (Kim \& Kankanhalli, 2009; Polites \& Karahanna, 2012). Hence, a higher-level of switching benefit will increase the behavior intention to use the new HR tool. A positive behavior intention to use the new tool would mean more adoption and use of the tool (Venkatesh et al., 2003). Past studies show that incumbent system usage constructs can be directly linked to behavior intention to use new system (Polites \& Karahanna, 2012). Thus, we formulate the hypothesis that behavior intention to use has a positive impact on actual use of the new MyKaal sheet tool. Similarly, the behavioral intention to use the technology also would mean that the resistance to the tool is no longer high and therefore their user resistance should be negatively impacted. Thus, we posit the below:

H8: Switching benefits will positively impact behavior intention to use H9: Behavior intention to use will positively impact IT use.

H10: Behavior intention to use will negatively impact IT user resistance.

\section{Method}

\section{Data Collection, Pre and Pilot Testing}

We used survey method to gather data. All items were based on prior literature. We administrated the survey to employees of GOODTECH, Information system department members situated in France through e-mail. Survey is a widely used method and has been depicted is "an excellent vehicle for measuring a wide variety of unobservable data"(Bhattacherjee, 2012). All scales were adapted from (Kim \& Kankanhalli, 2009) with behavior intention to use scale adopted from (Venkatesh et al., 2012).

Since survey questions were originally prepared in English, and translated to French, to cater to the target population (Bhattacherjee, 2012) (p73), we also undertook a pre-test for content 
readability and relevance with the unit manager of the HR IT department of GOOGTECH. This was followed by a pilot test with a working group composed of 5 IT HR domain members who had both English and French language competencies. The French translations were further refined using their help before the survey was distributed to the entire Information Systems department composed of 400 employees within the GOODTECH firm. The participation in the survey was both anonymous and voluntary. The survey remained open for 3 weeks and a total of 103 valid responses were collected for final analysis.

Out of 103 survey responses received, 51 were male and 52 were from female respondents. The average age of the respondent was 29 years. In terms of their tenure within the company, 56 respondents were under 3 years. 23 respondents were between 4 to 6 years tenure, 5 responents had between 7 to 9 years tenure and 19 respondents had more than 9 years of tenure. The respondents both managers (21) and non-managers (82).

\section{Instrument Validation and Data Analysis}

For the data analysis, we used Partial Least Squares (PLS), a latent structural equation modeling technique, as implemented in Smart PLS 3.0, which utilizes a component-based path modeling application (Ringle et al., 2005). PLS avoids the two major problems of inadmissible solutions and factor indeterminacy and thus is appropriate for analyzing complex models with latent variables with small sample sizes as well (Fornell \& Bookstein, 1982; Pavlou \& Gefen, 2005). Various prior IS studies have employed PLS and found it to be an effective method for data analysis (Shirish, 2020a; Srivastava \& Chandra, 2018; Teo et al., 2008). Following the recommended two-stage analytical procedure (Anderson \& Gerbing, 1988; Hair et al., 1998), 
the first stage of data analysis evaluates the measurement properties of the constructs, while the second stage examines the structural relationships.

We tested three types of validity: content validity, convergent validity, and discriminant validity. Content validity assesses whether the chosen measures appropriately capture the full domain of the construct (Straub et al., 2004). We examined content validity by checking for consistency between the measurement items and the existing literature at the stage of survey design. Convergent validity checks that the indicators for a construct are more correlated with one another than with the indicators of another construct (Petter et al., 2007). Most variables were those directly adapted from the reference provided in the original paper (Kim \& Kankanhalli, 2009). Behavior intention to use variable was adapted from (Venkatesh et al., 2012) and IT use was measured as the actual use of the MyKaalsheet grouped into the frequency of 3 months usage before the survey was taken. Objective inputs from the system were extracted for this variable. The raw data was categorized into a range from 'none' to 'more than 4 times' of HR tool usage in the last three months.

Next, for instrumentation purposes, we tested the measurement model with IT use and IT user resistance as our dependent variables. Factor analysis showed that there is a strong correlation between each of the items and their corresponding construct. This demonstrates convergent validity. We tested convergent validity by examining the composite reliability (CR) and average variance extracted (AVE: the ratio of the construct variance to the total variance among indicators) for the indicators (Hair et al., 1998). We note that 0.70 is the suggested CR threshold for reliable measurement (Chin, 1998). As seen in Table 2, the CR values ranged from .876 to .942 , above the threshold. AVE was satisfactory with values ranging from .641 to .891 and thus above the recommended threshold of 0.50 (Fornell \& Larcker, 1981). The high Cronbach's 
alpha values, ranging from .899 to .929 confirm the reliability of the scales for all the constructs.

\begin{tabular}{|l|l|l|l|l|}
\hline & Cronbach's Alpha & rho_A & $\begin{array}{l}\text { Composite } \\
\text { Reliability }\end{array}$ & $\begin{array}{l}\text { Average Variance } \\
\text { Extracted (AVE) }\end{array}$ \\
\hline Age & 1.000 & 1.000 & 1.000 & 1.000 \\
\hline BIU & 0.899 & 0.906 & 0.937 & 0.833 \\
\hline COP & 0.808 & 0.842 & 0.887 & 0.725 \\
\hline GEN & 1.000 & 1.000 & 1.000 & 1.000 \\
\hline OS & 0.929 & 0.939 & 0.955 & 0.875 \\
\hline POS & 1.000 & 1.000 & 1.000 & 1.000 \\
\hline SEC & 0.895 & 0.938 & 0.934 & 0.825 \\
\hline SWB & 0.844 & 0.856 & 0.894 & 0.679 \\
\hline SWC & 0.814 & 0.864 & 0.876 & 0.643 \\
\hline TEN & 1.000 & 1.000 & 1.000 & 1.000 \\
\hline UR & 0.858 & 0.874 & 0.899 & 0.641 \\
\hline Use & 0.879 & 0.902 & 0.942 & 0.891 \\
\hline N & BIU & 0.9072 & \\
\hline
\end{tabular}

Note : BIU-Behavioral Intention to use; COP-Colleagues Opinion; GEN-Gender; OS-Organizational support for change; PO-Position; SEC: Self efficacy for change; SWB-Switching Benefits; SWCSwitching costs; TEN-Tenure; UR-IT User resistance; Use-IT Use

Table 2: Measurement Model for Assessment for Reflective Constructs

We verified the discriminant validity of the various constructs by checking the square root of the AVE, as recommended by Fornell and Larcker (1981). The values of the square root of the AVEs (shown on the diagonal in Table 3) are all greater than the corresponding inter construct correlations (the off-diagonal entries in Table 3), exhibiting satisfactory discriminant validity. We also checked the cross-loadings of the items on other constructs, which were quite low indicating discriminant validity.

\begin{tabular}{|l|l|l|l|l|l|l|l|l|l|l|l|l|}
\hline & Age & BIU & COP & GEN & OS & PO & SEC & SWB & SWC & TEN & UR & Use \\
\hline Age & $\mathbf{1 . 0 0 0}$ & & & & & & & & & & & \\
\hline BIU & -0.185 & $\mathbf{0 . 9 1 2}$ & & & & & & & & & & \\
\hline COP & -0.217 & 0.679 & $\mathbf{0 . 8 5 1}$ & & & & & & & & & \\
\hline GEN & -0.189 & 0.023 & 0.110 & $\mathbf{1 . 0 0 0}$ & & & & & & & & \\
\hline OS & -0.066 & 0.411 & 0.414 & 0.074 & $\mathbf{0 . 9 3 6}$ & & & & & & & \\
\hline PO & -0.307 & -0.055 & -0.006 & 0.147 & 0.095 & $\mathbf{1 . 0 0 0}$ & & & & & & \\
\hline SEC & 0.014 & 0.430 & 0.305 & -0.060 & 0.388 & -0.003 & $\mathbf{0 . 9 0 8}$ & & & & & \\
\hline SWB & -0.240 & 0.636 & 0.402 & 0.085 & 0.442 & 0.148 & 0.328 & $\mathbf{0 . 8 2 4}$ & & & & \\
\hline SWC & 0.136 & -0.467 & -0.353 & 0.035 & -0.191 & -0.070 & -0.376 & -0.211 & $\mathbf{0 . 8 0 2}$ & & & \\
\hline TEN & 0.802 & -0.129 & -0.137 & -0.075 & -0.021 & -0.285 & 0.059 & -0.200 & 0.027 & $\mathbf{1 . 0 0 0}$ & & \\
\hline
\end{tabular}




\begin{tabular}{|l|l|l|l|l|l|l|l|l|l|l|l|l|}
\hline UR & 0.099 & -0.626 & -0.488 & 0.024 & -0.227 & -0.058 & -0.235 & -0.296 & 0.670 & 0.087 & $\mathbf{0 . 8 0 1}$ & \\
\hline Use & -0.159 & 0.563 & 0.386 & 0.020 & 0.268 & -0.056 & 0.345 & 0.287 & -0.417 & -0.143 & -0.416 & $\mathbf{0 . 9 4 4}$ \\
\hline
\end{tabular}

Note : BIU-Behavior Intention to use; COP-Colleagues Opinion; GEN-Gender; OS-Organizational support for change; PO-Position; SEC: Self efficacy for change; SWB-Switching Benefits; SWC-Switching costs; TEN-Tenure; UR-IT User resistance; Use-IT Use

\section{Table 3: Fornell-Larcker Criterion}

As the sample size of this study was 103 , we checked the acceptable smallest sample size to detect the effect of regression analysis at $p<0.05$ using $\mathrm{G}^{*}$ Power (Faul et al., 2009). The desired power level is typically 0.80 , but the researcher performing power analysis can specify the higher level, such as 0.90 . The power analysis results for our study revealed the smallest acceptable sample size of 73 for the power level of 0.95 which means that that there is a $95 \%$ probability our research will not commit a type II error. As seen in Figure 3, the G power plot give us the confidence that our sample size of 103 respondents is valid to offer significant results.

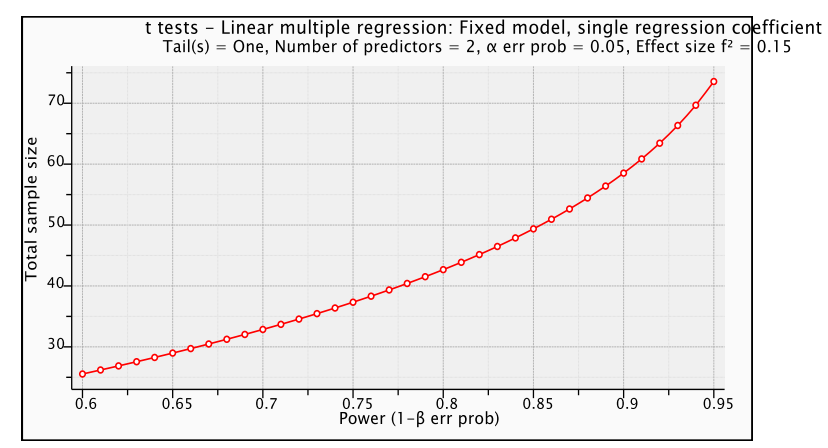

Figure 3: Power Analysis for Determining Sample Size

Together, our results above indicate a satisfactory measurement model paving the way for subsequent structural model analysis.

\section{Results}

\begin{tabular}{|c|c|c|c|c|c|}
\hline \multirow[t]{2}{*}{ Variables } & Switching Costs & $\begin{array}{l}\text { Switching } \\
\text { Benefits }\end{array}$ & $\begin{array}{l}\text { Behavioral } \\
\text { Intention to } \\
\text { Use }\end{array}$ & IT use & $\begin{array}{ll}\text { IT } & \text { user } \\
\text { resistance }\end{array}$ \\
\hline & $(\mathrm{t})$ & $(\mathrm{t})$ & \begin{tabular}{l|l}
$\beta$ & $(\mathrm{t})$
\end{tabular} & $(\mathrm{t})$ & $(\mathrm{t})$ \\
\hline $\begin{array}{l}\text { Control } \\
\text { Variables }\end{array}$ & & & & & \\
\hline Age & & & & $0.038(0.278)$ & $-0.184(1.711)$ \\
\hline
\end{tabular}




\begin{tabular}{|c|c|c|c|c|c|}
\hline Gender & & & & $0.026(0.301)$ & $-0.001(0.020)$ \\
\hline Tenure & & & & $-0.127(0.897)$ & $0.145(1.420)$ \\
\hline Position & & & & $-0.075(0.787)$ & $-0.066(1.049)$ \\
\hline $\begin{array}{l}\text { Org. Supp } \\
\text { for Change }\end{array}$ & & & & & $0.044(0.613)$ \\
\hline $\begin{array}{l}\text { Focal } \\
\text { Variables }\end{array}$ & & & & & \\
\hline $\begin{array}{l}\text { Self- } \\
\text { efficacy } \\
\text { for Change }\end{array}$ & $-\mathbf{- 0 . 2 9 6} * *(3.466)$ & & & & \\
\hline $\begin{array}{l}\text { Colleagues } \\
\text { Opinion }\end{array}$ & $\mathbf{- 0 . 2 6 3} * *(2.921)$ & $0.402 * *(5.696)$ & & & \\
\hline $\begin{array}{l}\text { Switching } \\
\text { Cost }\end{array}$ & & & $-\mathbf{0 . 3 4 9} * *(5.309)$ & $\mathbf{- 0 . 2 1 6}^{* *}(2.328)$ & $\mathbf{0 . 4 9 5}^{* * *(5.090)}$ \\
\hline $\begin{array}{l}\text { Switching } \\
\text { Benefits }\end{array}$ & & & $\mathbf{0 . 5 6 2} * *(9.787)$ & & \\
\hline $\begin{array}{l}\text { Behavioral } \\
\text { Intention } \\
\text { to Use }\end{array}$ & & & & $\mathbf{0 . 4 4 7 * * ( 4 . 7 8 9 )}$ & $\mathbf{- 0 . 4 3 1} * *(4.373)$ \\
\hline $\begin{array}{l}\text { Indirect } \\
\text { Effect } \\
\text { SWC- } \\
\text { BIU- } \\
\text { UR/USE }\end{array}$ & & & & $-1.56 * *(3.821)$ &. $\mathbf{1 5 0} * *(3.032)$ \\
\hline $\mathrm{R}^{2}$ & .204 & .16 & .521 & .358 & .590 \\
\hline
\end{tabular}

Table 4: Structural Model Results

For the evaluation of the predictive relevance of the structural model, the Stone and Geisser $\mathrm{Q}^{2}$ test was performed using the blindfolding procedure (Geisser, 1974; Stone, 1974). The blindfolding test, which was conducted with omission distance equals to 7 (the recommended number), revealed that all $\mathrm{Q}^{2}$ values of the endogenous variables were greater than zero. $\mathrm{A}$ Positive $\mathrm{Q}^{2}$ values provide evidence of the predictive relevance despite the small sample size used in this study.

The $\mathrm{R}^{2}$ values allows us to conclude that behavior intention to use via switching cost and switching benefits and controls can explain together 59 percent of IT user resistance and 35 percent of IT use. We are also able to predict 52 percent of the behavioral intention to use which is depended on switching costs and switching benefits perceptions. The reading of the 
Table 4 allows us to conclude that all hypothesis proposed in this study are proven. Table 4 and 5 provides the path coefficient values of all the relationship and their significant level supporting all our proposed hypotheses from H1 - H10. Further, we note the indirect effects of the variable behavior intention to use on IT use and IT user resistance with $\beta$ and t values $1.56^{* *}(3.821)$ and $.150 * *(3.032)$ respectively are significant. Thus, we can conclude there is a mediation to support hypotheses H4 and H5 in the model. Behavior intention to use partially mediates the relationship between switching costs and IT use and IT user resistance behavior.

\begin{tabular}{|l|l|l|}
\hline Hypotheses Proposed & $\boldsymbol{\beta}$ & Results \\
\hline H1: Self efficacy for change will negatively impact switching cost. & $-0.296^{* *}$ & Supported \\
\hline H2: Switching costs will negatively impact IT use. & $-0.216^{* *}$ & Supported \\
\hline $\begin{array}{l}\text { H3: Switching costs will positively impact IT user resistance } \\
\text { H4: Behavior intention to use mediates the relationship between switching costs } \\
\text { and IT use. }\end{array}$ & $-1.56^{* *}$ & Supported \\
\hline $\begin{array}{l}\text { H5: Behavior intention to use mediates the relationship between switching costs } \\
\text { and IT user resistance. }\end{array}$ & $.150^{* *}$ & Supported \\
\hline $\begin{array}{l}\text { H6: Favorable colleagues opinion will have a negative impact on switching costs } \\
\text { H7: Favorable colleagues opinion will have a positive impact on switching } \\
\text { benefits }\end{array}$ & $-0.263^{* *}$ & Supported \\
\hline $\begin{array}{l}\text { H8: Switching benefits will positively impact behavior intention to use } \\
\text { H9: Behavior intention to use will positively impact IT use. }\end{array}$ & Supported \\
\hline $\begin{array}{l}\text { H10: Behavior intention to use will negatively impact IT user resistance. } \\
\text { Note: } \beta \text { is the path coefficient value; ** means a p value of less than .05 }\end{array}$ & $-0.431^{* *}$ & Supported \\
\hline
\end{tabular}
Table 5: Summary of Results

\section{Implications, Limitations and Future Research Directions}

This study makes key contributions to IS and organizational change management research. First, by providing a conceptual replication of the comprehensive theoretically grounded model of URM, we are addressing the need for more replication studies in the IS field (Dennis \& Valacich, 2014; Samhan \& Joshi, 2019). The replication allowed us to offer partial validity to the URM model. We provide cross-cultural validity to the model and its measurement items in 
a French context. Second, this study helps in strengthening the theory on IT user resistance by examining the original research model in a different environment such as the HR IT department in France (Dennis \& Valacich, 2014). Replicating the URM in a new context shows that this model, if appropriately modified, could be adapted to explain resistance as well as adoption of technologies in mandatory use of newly implemented information systems in post implementation stages as well. Thus, the enriched user adoption and resistance model expands the ambit of prior literature in user resistance by offering a valid theoretical framework to understand user resistance and adoption in post implementation stages of technological renewals or other technology change management initiatives in organizations.

This study suggests that the constructs of the URM when enriched with adoption specific variable are relevant in post implementation of IT contexts. We therefore address calls made to contextualize IT implementation success and failure factors (Dwivedi et al., 2015) and also contribute to studies that look at dual notion of inhibitor and facilitator to IT use in empirical settings. (Cenfetelli, 2004; Tsai et al., 2019)

Third, this study's findings advance the theoretical understanding of the factors that shape resistance and adoption to new HR IT tool. To our knowledge, this is the first study that comprehensively models the antecedents to predict and explain resistance and adoption of HR IT tool amongst IT employees as end users. By enriching the existing URM with adoption variable of behavioral intention of use instead of perceived value we provide a parsimonious theory to examine both user adoption and resistance in the context of new HR IT tool implementation. Thus, we offer a robust model that can be used as a foundation to build and develop future models to better understand the HR IT tool use and resistance phenomenon. 
Further, we note that organizational support did not have an effect on user resistance and none of the control variables as discussed in the URM model proved relevant in the context of IT employee use of HR tool.

The indirect effect of behavioral intention to use on user resistance and IT use is a significant addition that should motivate future work to uncover additional costs and benefits surrounding behavioral intention to use. In addition, future work could also examine how these perceived costs and benefits vary across different demographic groups. We note that IT department employees, despite their positive attitude towards new technology, can manifest resistance, which can also retard new technology renewals due to tardive user adoption. Thus, companies need to re-consider if IT department members must be considered as change ambassadors and champions when introducing HR IT change within organization. Impact of resistance and adoption need to be further studied (Beaudry et al., 2020). This decision can affect change management strategies and interventions. The amount of training that needs to be provided to IT department employees in order to build their self-efficacy perception may need reevaluation. Social climate in which the change is introduced is another crucial element to conduct further research. The findings show that implementers can rely on colleague's opinion for successful technology renewals in HR IT domain. Moreover, our findings reveal that demographic indicators such as age, gender, position, tenure are not significant, in explaining HR IT tool use or resistance. Finally, the study offers partial validity to URM model variables from a French HR tool implementation context.

Future research needs to examine the role individual level differences when examining dual focus models. Particularly it will be interesting to look at individual level technology framing of IT department employees to know if they will perceive the change as positive or negative (Shirish, 2020b). Moreover, recent research has tried to integrate social, task-related, and personal factors of resistance by understanding how IT identity threat can cause IT resistance 
(Craig et al., 2019). It will be interesting to examine in future research how this variable may either directly or as a moderator impact switching cost and switching benefits expounded in the enriched post adoption URM model amongst IT professionals. Researchers have called for a more nuanced explanation of the bias perceptions in post implementation phases, this model should be further expanded to include other pertinent variables such as loss aversion, regret avoidance and anchoring effects (Lee \& Joshi, 2017).

Before moving on to practical implications of the study. We believe that we need to list out certain limitations of this study. The findings of this study are very context dependent and domain dependent focused on specific end users from a large France corporation. Further studies should to test the enriched model both prior to technology renewal and post technology renewals.

Researchers should use both qualitative and quantitative techniques to study IT use and resistance. Mixed methods study will be more suited to investigate complex interorganizational information systems implementation initiatives specifically (Premkumar \& Ramamurthy, 1995; Valeri \& Baggio, 2020c). These technological initiatives can be impacted by national culture particularities and intermediary network dynamics as demonstrated in past studies in the tourism sector (Baggio \& Valeri, 2020; Valeri \& Baggio, 2020a, 2020b).

Moreover, we have restricted our model to post implementation phase of technology renewal within a multinational organization in France, which allows us to measure actual IT use through system records. However, empirically testing a partial model that measures user resistance as the only dependent variable may be useful for a pre-implementation phase. In this study, we have not measured the key construct of "perceived value" as proposed in the original model. Future research should include perceived value and behavior intention to use together and test the model's predictive relevance. 
Moreover, since the sample is restricted to only IT savvy employees, it may be interesting to expand this study by incorporating diverse sample to validate the enriched URM model proposed. Although a proper translation of English scales to French was effectuated for the purposes of this study, it may be prudent to use a professional translator when adapting scales from English language to other languages. However, our analysis did not see any measurement error in any of the instruments used in this study, so this issue does not challenge the validity of the findings.

Our study provides a number of implications to practice. First, we provide possible solutions to organizations trying to reduce resistance and increase adoption to new HR IT system. Switching cost has a direct effect on resistance and IT use. Thus, reducing it may be critical when aiming to eliminate resistance and increase adoption of new tools. This could be achieved by enhancing positive opinions about the change through peer and mentor networks. Additionally, investing in IT employees' professional development will increase their selfefficacy for change perceptions, which will negatively impact their inertia perceptions and propel them to switch to a new HR tool. Moreover, it is important to emphasize the advantages of the HR tool and to explain the core benefits of this switch at early stages of implementation of the HR tools. Follow up after initial implementation stages to ensure the message percolates will further ensure that the organization intent is well communicated and sustained even after initial implementation phases (Beaudry et al., 2020). This would help in increasing switching benefits and behavior intention to use the tool as passive users looking for workarounds would be convert to a more active user of the new tool. Finally, the findings would help practitioners understand HR tool resistance in the context of a French based large multinational firm in which this study was conducted. We believe that the findings of this study and the proposed model will serve as the first step toward evaluating and devising means to solve one of the 
long-standing and persistent technology change management problem associated with IT user resistance and adoption issues amongst IT employees specifically.

\section{References}

Abrahamson, E. (2004). Avoiding repetitive change syndrome. MIT Sloan Management Review, 45(2), 93.

Ajzen, I. (1991). The theory of planned behavior. Organizational behavior and human decision processes, 50(2), 179-211.

Ajzen, I. (2002). Perceived Behavioral Control, Self-Efficacy, Locus of Control, and the Theory of Planned Behavior. Journal of Applied Social Psychology, 32(1), 1-20.

Anderson, J. C., \& Gerbing, D. W. (1988). Structural equation modeling in practice: A review and recommended two-step approach. Psychological Bulletin, 103(3), 411.

Baggio, R., \& Valeri, M. (2020). Network science and sustainable performance of family businesses in tourism. Journal of Family Business Management.

Bandura, A. (1995). Self-efficacy in changing societies. Cambridge university press.

Bareil, C. (2004). La résistance au changement: synthèse et critique des écrits. HEC Montréal, Centre d'études en transformation des organisations.

Barki, H., Titah, R., \& Boffo, C. (2007). Information system use-related activity: an expanded behavioral conceptualization of individual-level information system use. Information Systems Research, 18(2), 173-192.

Beaudry, A., \& Pinsonneault, A. (2005). Understanding user responses to information technology: A coping model of user adaptation. MIS quarterly, 493-524.

Beaudry, A., Vaghefi, I., Bagayogo, F., \& Lapointe, L. (2020). Impact of IT User Behavior: Observations through a New Lens. Communications of the Association for Information systems, $46(1), 15$.

Bhattacherjee, A. (2012). Social science research: Principles, methods, and practices.

Brown, S. A., \& Venkatesh, V. (2005). Model of adoption of technology in households: A baseline model test and extension incorporating household life cycle. MIS quarterly, 399-426.

Burnkrant, R. E., \& Cousineau, A. (1975). Informational and normative social influence in buyer behavior. Journal of Consumer research, 2(3), 206-215.

Cenfetelli, R. T. (2004). Inhibitors and enablers as dual factor concepts in technology usage. Journal of the Association for Information Systems, 5(11), 16.

Chandra, S., Shirish, A., \& Srivastava, S. C. (2020). Theorizing technological spatial intrusion for ICT enabled employee innovation: the mediating role of perceived usefulness. Technological Forecasting and Social Change, 161, 120320.

Chin, W. W. (1998). The partial least squares approach to structural equation modeling. Modern methods for business research, 295(2), 295-336.

Collerette, P., Delisle, G., \& Perron, R. (1997). Le changement organisationnel: théorie et pratique. PUQ.

Compeau, D., Higgins, C. A., \& Huff, S. (1999). Social cognitive theory and individual reactions to computing technology: A longitudinal study. MIS quarterly, 145-158.

Compeau, D. R., \& Higgins, C. A. (1995). Computer self-efficacy: Development of a measure and initial test. MIS quarterly, 189-211.

Craig, K., Thatcher, J. B., \& Grover, V. (2019). The IT identity threat: A conceptual definition and operational measure. Journal of management information systems, 36(1), 259-288. 
Davis, F. D. (1989). Perceived usefulness, perceived ease of use, and user acceptance of information technology. MIS quarterly, 319-340.

Dennis, A., Brown, S. A., Wells, T. M., \& Rai, A. (2020). Editor's Comments: Replication Crisis or Replication Reassurance: Results of the IS Replication Project. Management Information Systems Quarterly, 44(3), iii-x.

Dennis, A. R., \& Valacich, J. S. (2014). A Replication Manifesto. AIS Transactions on Replication Research. 1, 1-5.

Dent, E. B., \& Goldberg, S. G. (1999). Challenging "resistance to change". The Journal of applied behavioral science, 35(1), 25-41.

Dwivedi, Y. K., Wastell, D., Laumer, S., Henriksen, H. Z., Myers, M. D., Bunker, D., Elbanna, A., Ravishankar, M., \& Srivastava, S. C. (2015). Research on information systems failures and successes: Status update and future directions. Information Systems Frontiers, 17(1), 143-157.

Fan, Y.-W., Chen, C.-D., Wu, C.-C., \& Fang, Y.-H. (2015). The effect of status quo bias on cloud system adoption. Journal of Computer Information Systems, 55(3), 55-64.

Faul, F., Erdfelder, E., Buchner, A., \& Lang, A.-G. (2009). Statistical power analyses using G* Power 3.1: Tests for correlation and regression analyses. Behavior research methods, 41(4), 11491160 .

Ferneley, E. H., \& Sobreperez, P. (2006). Resist, comply or workaround? An examination of different facets of user engagement with information systems. European Journal of Information Systems, 15(4), 345-356.

Forbes. (2020). 14 Noteworthy Aspects Of Digital Transformation In HR. Retrieved 20 october 2020 from https://www.forbes.com/sites/forbeshumanresourcescouncil/2020/07/27/14-noteworthyaspects-of-digital-transformation-in-hr/\#5ef86e9f5a50

Fornell, C., \& Bookstein, F. L. (1982). Two structural equation models: LISREL and PLS applied to consumer exit-voice theory. Journal of marketing research, 19(4), 440-452.

Fornell, C., \& Larcker, D. F. (1981). Evaluating structural equation models with unobservable variables and measurement error. Journal of marketing research, 18(1), 39-50.

Geisser, S. (1974). A predictive approach to the random effect model. Biometrika, 61(1), 101-107.

Hair, J. F., Black, W. C., Babin, B. J., Anderson, R. E., \& Tatham, R. L. (1998). Multivariate data analysis (Vol. 5). Prentice hall Upper Saddle River, NJ.

Hirschheim, R., \& Newman, M. (1988). Information systems and user resistance: theory and practice. The Computer Journal, 31(5), 398-408.

Inder, B., \& O'Brien, T. (2003). The endowment effect and the role of uncertainty. Bulletin of Economic Research, 55(3), 289-301.

Johns, G. (2006). The essential impact of context on organizational behavior. Academy of management review, 31(2), 386-408. 
Joshi, K. (1991). A model of users' perspective on change: the case of information systems technology implementation. MIS quarterly, 229-242.

Kahneman, D., \& Tversky, A. (1979). On the interpretation of intuitive probability: A reply to Jonathan Cohen.

Kane, G. C., \& Labianca, G. (2011). IS avoidance in health-care groups: A multilevel investigation. Information Systems Research, 22(3), 504-522.

Kim, H.-W., \& Kankanhalli, A. (2009). Investigating user resistance to information systems implementation: A status quo bias perspective. MIS quarterly, 567-582.

Kim, J. U., \& Kishore, R. (2019). Do we fully understand information systems failure? An exploratory study of the cognitive schema of IS professionals. Information Systems Frontiers, 21(6), 13851419 .

Kossek, E. E., Young, W., Gash, D. C., \& Nichol, V. (1994). Waiting for innovation in the human resources department: Godot implements a human resource information system. Human Resource Management, 33(1), 135-159.

Lapointe, L., \& Rivard, S. (2005). A multilevel model of resistance to information technology implementation. MIS quarterly, 461-491.

Lee, K., \& Joshi, K. (2017). Examining the use of status quo bias perspective in IS research: need for re-conceptualizing and incorporating biases. Information Systems Journal, 27(6), 733-752.

Marakas, G. M., \& Hornik, S. (1996). Passive resistance misuse: overt support and covert recalcitrance in IS implementation. European Journal of Information Systems, 5(3), 208-219.

Markus, M. L. (1983). Power, politics, and MIS implementation. Communications of the ACM, 26(6), 430-444.

Moore, G. C., \& Benbasat, I. (1991). Development of an instrument to measure the perceptions of adopting an information technology innovation. Information Systems Research, 2(3), 192-222.

Paré, G., \& Jutras, J.-F. (2004). How Good Is the Professional's Aptitude in the Conceptual Understanding of Change Management? Communications of the Association for Information systems, 14(1), 31 .

Pavlou, P. A., \& Gefen, D. (2005). Psychological contract violation in online marketplaces: Antecedents, consequences, and moderating role. Information Systems Research, 16(4), 372399.

Petter, S., Straub, D., \& Rai, A. (2007). Specifying formative constructs in information systems research. MIS quarterly, 623-656.

Polites, G. L., \& Karahanna, E. (2012). Shackled to the status quo: The inhibiting effects of incumbent system habit, switching costs, and inertia on new system acceptance. MIS quarterly, 21-42.

Premkumar, G., \& Ramamurthy, K. (1995). The role of interorganizational and organizational factors on the decision mode for adoption of interorganizational systems. Decision sciences, 26(3), 303-336. 
Ringle, C. M., Wende, S., \& Will, A. (2005). SmartPLS 2.0.

Sam, H. K., Othman, A. E. A., \& Nordin, Z. S. (2005). Computer self-efficacy, computer anxiety, and attitudes toward the Internet: A study among undergraduates in Unimas. Journal of Educational Technology \& Society, 8(4), 205-219.

Samhan, B., \& Joshi, K. (2019). Switching to Electronic Health Record Systems: A Replication of the User Resistance Model. AIS Trans. Replication Res., 5, 11.

Samuelson, W., \& Zeckhauser, R. (1988). Status quo bias in decision making. Journal of risk and uncertainty, 1(1), 7-59.

Selander, L., \& Henfridsson, O. (2012). Cynicism as user resistance in IT implementation. Information Systems Journal, 22(4), 289-312.

Shirish, A. (2020a). Cognitive-affective appraisal of technostressors by ICT-based mobile workers and their impacts on technostrain. Human Systems Management(Pre-press), 1-21.

Shirish, A. (2020b). Cognitive-affective appraisal of technostressors by ICT-based mobile workers and their impacts on technostrain. Human Systems Management(Preprint), 1-21.

Srivastava, S. C., \& Chandra, S. (2018). Social presence in virtual world collaboration: An uncertainty reduction perspective using a mixed methods approach. MIS quarterly, 42(3), 779-804.

Stone, M. (1974). Cross-validatory choice and assessment of statistical predictions. Journal of the Royal Statistical Society: Series B (Methodological), 36(2), 111-133.

Straub, D., Boudreau, M.-C., \& Gefen, D. (2004). Validation guidelines for IS positivist research. Communications of the Association for Information systems, 13(1), 24.

Taylor, S., \& Todd, P. A. (1995). Understanding information technology usage: A test of competing models. Information Systems Research, 6(2), 144-176.

Teo, T. S., Srivastava, S. C., \& Jiang, L. (2008). Trust and electronic government success: An empirical study. Journal of Management Information Systems, 25(3), 99-132.

Tsai, J.-M., Cheng, M.-J., Tsai, H.-H., Hung, S.-W., \& Chen, Y.-L. (2019). Acceptance and resistance of telehealth: The perspective of dual-factor concepts in technology adoption. International Journal of Information Management, 49, 34-44.

Valeri, M., \& Baggio, R. (2020a). A critical reflection on the adoption of blockchain in tourism. Information Technology \& Tourism, 1-12.

Valeri, M., \& Baggio, R. (2020b). Italian tourism intermediaries: A social network analysis exploration. Current Issues in Tourism, 1-14.

Valeri, M., \& Baggio, R. (2020c). Social network analysis: Organizational implications in tourism management. International Journal of Organizational Analysis.

Van Offenbeek, M., Boonstra, A., \& Seo, D. (2013). Towards integrating acceptance and resistance research: evidence from a telecare case study. European Journal of Information Systems, 22(4), 434-454. 
Venkatesh, V., Morris, M. G., Davis, G. B., \& Davis, F. D. (2003). User acceptance of information technology: Toward a unified view. MIS quarterly, 425-478.

Venkatesh, V., Thong, J. Y., \& Xu, X. (2012). Consumer acceptance and use of information technology: extending the unified theory of acceptance and use of technology. MIS quarterly, 157-178.

Visinand, M. (2004). Le rôle attendu des professionnels $R H$ lors d'un changement organisationnel

Warshaw, P. R., \& Davis, F. D. (1985). Disentangling behavioral intention and behavioral expectation. Journal of experimental social psychology, 21(3), 213-228.

Wimelius, H., Mathiassen, L., Holmström, J., \& Keil, M. (2020). A paradoxical perspective on technology renewal in digital transformation. Information Systems Journal, 1-28. https://doi.org/10.1111/isj.12307

Xiaofei, Z., Guo, X., Ho, S. Y., Lai, K.-h., \& Vogel, D. (2020). Effects of Emotional Attachment on Mobile Health-Monitoring Service Usage: An Affect Transfer Perspective. Information \& Management, 103312.

Zahir Irani, P. E. (2000). The propagation of technology management taxonomies for evaluating investments in information systems. Journal of management information systems, 17(3), 161177.

Appendix 1: Key Research on IT use and resistance in Information Systems Domain

\begin{tabular}{|c|c|c|}
\hline Perspective & Source & Domain Maturity \\
\hline IT adoption related & $\begin{array}{l}\text { (Barki et al., 2007; Beaudry \& } \\
\text { Pinsonneault, 2005; Compeau \& } \\
\text { Higgins, 1995; Davis, 1989; Moore \& } \\
\text { Benbasat, 1991; Taylor \& Todd, 1995; } \\
\text { Venkatesh et al., 2003) }\end{array}$ & $\begin{array}{l}\text { Highly Mature (Several } \\
\text { validations and follow up } \\
\text { work have been undertaken, } \\
\text { which includes contextual } \\
\text { developments) }\end{array}$ \\
\hline IT resistance related & $\begin{array}{l}\text { (Craig et al., 2019; Ferneley \& } \\
\text { Sobreperez, 2006; Kane \& Labianca, } \\
\text { 2011; Kim \& Kankanhalli, 2009; } \\
\text { Lapointe \& Rivard, 2005; Marakas \& } \\
\text { Hornik, 1996; Markus, 1983; Selander } \\
\text { \& Henfridsson, 2012) }\end{array}$ & $\begin{array}{l}\text { Relatively Mature (Several } \\
\text { new concepts continue to } \\
\text { emerge and core models } \\
\text { continue to be validated) }\end{array}$ \\
\hline Dual focus & $\begin{array}{l}\text { (Beaudry et al., 2020; Cenfetelli, 2004; } \\
\text { Tsai et al., 2019; Van Offenbeek et al., } \\
\text { 2013) and the current study. }\end{array}$ & $\begin{array}{l}\text { Emerging (Research is limited } \\
\text { and fragmented) }\end{array}$ \\
\hline
\end{tabular}

